\title{
Fabrikasyon Ortamında Üretilen Orta Yoğunluktaki Liflevhaların (MDF) Yanma Özelliklerinin İncelenmesi
}

\author{
Cengiz GÜLER ${ }^{1 *}$, Ömer Erdem ŞİMŞEK ${ }^{2}$ \\ ${ }^{1}$ Düzce Üniversitesi, Orman Fakültesi, Orman Endüstri Mühendisliği Bölümü,81620, DÜZCE \\ ${ }^{2}$ Kastamonu Entegre Ağaç San. ve Tic. A.Ş, GEBZE
}

\section{Öz}

Odun esaslı kompozit malzemeler içerisinde en önemli ürünlerden biri de liflevhalardır. Liflevhalar lignoselülozik yapıları sebebiyle kolay yanabilme ve tutuşabilme gibi bazı dezavantajlara sahiptir. Bu durum özellikle toplu yaşam alanlarında can ve mal güvenliğini tehdit edici bir unsurdur. Mobilya ve benzeri birçok odun esaslı malzemenin insan sağlığı ve güvenliği açısından yanmaya karşı daha dayanıklı hale getirilmesi önem teşkil etmektedir. Özellikle çeşitli kullanım yerlerinde yanmaya karşı belirli bir dirence sahip olan odun esaslı levha ürünleri zorunlu olarak tercih edilmektedir. Bu çalışmada; EcoChem (FR) (Flame Retardand Chemistry) ticari adıyla bilinen yanma geciktirici özelliğe sahip amonyum polifosfat (APP) ile üretilen orta yoğunlukta liflevhaların (MDF) yanma özellikleri incelenmiştir. Hem kontrol örnekleri hem de yanmaya karşı dayanıklı MDF'ler, laboratuar ortamında direk aleve maruz bırakılarak karşılaştırılmıştır. Ayrıca termogravimetrik analiz yöntemi ile de incelenmiş̧tir. Sonuçta FR kimyasalı ile üretilen levhaların \% 30 oranında yanmaya karşı daha fazla direnç gösterdiği gözlenmiştir.

Anahtar Kelimeler: Yangın geciktirici, liflevha, amonyum polifosfat, yanma, termogravimetrik analiz.

\section{Investigation of Combustion Properties of Medium Density fiberboards (MDF) Produced in The Factory Environment}

\begin{abstract}
One of the most important products in wood based composite materials is the fiberboard. The fiberboard has some disadvantages such as easy flammability and ignition due to its lignocellulosic structure. This situation is a threat to the security of life and property, especially in public areas. It is important to make furniture and many other wood based materials more resistant to burning in terms of human health and safety. In particular, woodbased sheet products having a certain resistance to combustion in various applications are necessarily preferred. In this study; The combustion properties of medium density fibers (MDF) produced by ammonium polyphosphate (APP), which is known as EcoChem (FR) (Flame Retardand Chemistry), were investigated. Both the control samples and the fire resistant MDFs were compared to the flame flame in the laboratory. It was also examined by thermogravimetric analysis method. As a result, it was observed that the panels produced with FR chemical showed $30 \%$ more resistance to combustion.
\end{abstract}

Keywords: Fire retardant, fiberboard, Ammonium polyphosphate, flame, combistion, thermogravimetric analyses. 


\section{Giriş}

Liflevhalar başta mobilya olmak üzere birçok kullanım alanına sahip ahşap esaslı bir kompozit malzemedir. Yonga levhalara göre biraz daha ağır olmalarına rağmen kolay işlenebilmesi, lamba zıvana açılabilmesi, isteğe göre renk ve desen verilebilmesi gibi nedenler kullanım oranını gittikçe artırmaktadır (Eroğlu ve Usta, 2000).

$\mathrm{Bu}$ olumlu özelliklerinin yanı sıra liflevhalar, odun ve odun esaslı diğer levha ürünleri gibi bazı sakıncalı özelliklere de sahiptir. Bu sakıncalı özelliklerden önemli olanlarından biri materyalin kolay yanabilmesi ve tutuşabilmesidir. Lignoselülozik materyallerin tümü, yanıcı özelliklere sahip olmaları nedeniyle tutuşma sıcaklığına ulaştıklarında ve yanma için gereken ortamı bulduklarında kolaylıkla yanabilmekte, direnç özelliklerini kaybederek yanma esnasında zayıf dayanım gösterip can ve mal güvenliğini tehdit edebilmektedir. $\mathrm{Bu}$ durum göz önüne alındığında, odun esaslı materyallerin; yapılarda, inşaat sektöründe vb. kullanım alanlarında değerlendirilmesi sınırlı hale gelmekte, kullanılması durumunda ise dayanım özelliklerinin iyileştirilmiş olması gerekmektedir. Bu amaçla; malzemenin yanma karakteristiklerine etki edip dayanımlarını artırmak için çeşitli yanmayı geciktirici kimyasal maddelerle muamele edilerek güçlendirilmesi yönünde çalışmalar yapılmaktadır (Gu ve ark. 2007; Ellis ve Rowell, 1989; Kozlowski ve ark.1999).

Yangın; katı, sıvı ve gaz halindeki yanıcı maddelerin kontrol dışı yanma olayıdır. Yanma bir maddenin, yakıcı bir maddeyle birleşmesi sonucunda 1sı açığa çıkararak meydana getirdiği olayların tümü olarak ifade edilmektedir. Norman koşullarda havada max. \% 21 oranında oksijen bulunur. Fakat yanma olayının gerçekleşebilmesi için havada en az \% 14 dolayında oksijen bulunması gerektiği bilinmektedir (Peker ve Atılgan, 2015). Yangın alevlenebilmesi için belirli bir sıcaklığa ulaşması gerekir. Kuru haldeki odunun herhangi bir kıvılcıma gerek duyulmadan 220 0C lerde kendi kendine tutuşabildiği bilinmektedir. Yanma sırasında ahşap malzemede $170{ }^{\circ} \mathrm{C}$ ye kadar kuruma, $270{ }^{\circ} \mathrm{C}$ ye kadar $\mathrm{CO}, \mathrm{CO}_{2}$ ve su buharı çıkışı, 250-300 ${ }^{\circ} \mathrm{C}$ de de tutuşma meydana gelir (İstek ve ark 2017). Yanma olayının gerçekleşebilmesi için yanıcı madde, oksijen ve sıcaklık üçlüsünün bir araya gelmesi gerekir. Bunlardan herhangi biri olmazsa yanma olayı gerçekleşmesi mümkün değildir.

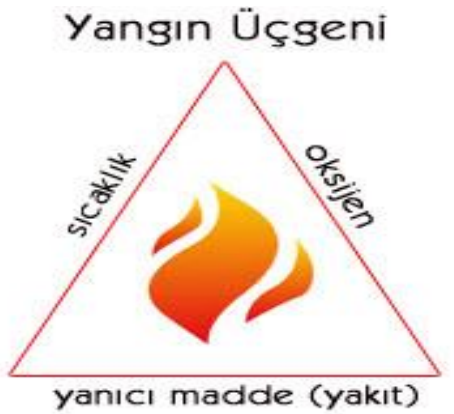

Şekil 1. a) Yangın üçgeni

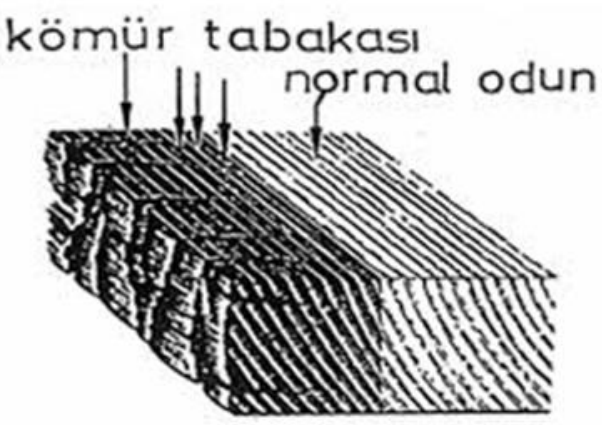

b) Ağaç malzemede kömürleşmenin oluşumu

Odun esaslı malzemelerin yanmasının geciktirilmesi ya da engellenmesi amacıyla yaygın olarak inorganik esaslı kimyasallar kullanılmaktadır. Bunlar amonyum sülfat, amonyum klorür, çinko klorür, borik asit ve boraks grubu kimyasallardır (Demir ve Aydın, 2016, Baysal, 2003). Yongalevha ve liflevha sektöründe ise üretim aşamasında tutkalla beraber ya da doğrudan lif veya yongaya katılarak uygulanabildiği gibi, normal levhalara çeşitli emprenye metotlarından (daldırma, firça ile süreme gibi) biri ile işlem yapılabilmektedir.

Yangın geciktirici kimyasal maddeler odun esaslı malzemelerin direnç özelliklerini, higroskopisiteye, özgül kütleye, korozifliğe, tutkallamaya, işlenebilmeye, yüzey pürüzlülüğüne ve 1sı iletkenliği üzerine olumlu veya olumsuz etkileri olduğunu ifade edilmektedir. (Demir ve Aydın, 2016).

Rejeesh ve Saju (2018) yapmış oldukları bir çalışmada Hindistan cevizi kabuğundan üretilen liflevhalara, boraks ve borik asitle muamele ettikten sonra yanmaya-alevlenmeye karşı direnci belirlemek amaciyla testler yapmış ve \% 35 oranında yanmaya karşı dirençli olduklarını tespit etmişlerdir. Hashim ve ark. (2005)'de alev geciktirici bir katkı maddesi olarak alüminyum trihidroksiti (ATH) belirli oranlarda kullanıp deneysel MDF levhalar üreterek testlere tabi tutmuşlardır. Sonuç olarak; kullanılan ATH'nin yangın geciktirici olarak kullanılabileceğini göstermişlerdir. Ustaömer ve ark. (2008)' da bor ile muamele edilmiş liflevhaların yüzey pürüzlülükleri üzerine etkisini incelemişlerdir. Ayrılmış ve ark. (2009) yaptıkları bir çalışmalarında, Fagus Orientalis Lipsky'den üretilen kaplamaları MAP, DAP, kireçli su ve BA+BX (ağırlıkça1:1) ile muamele 
etmişler ve bu kaplamaların fiziksel, mekanik ve yanma özelliklerini test etmişlerdir. Çalışma sonucunda ise, kireçli suyla muameleli örneklerin en iyi fiziksel özellikleri; BA+BX ile muameleli örneklerin ise en iyi mekanik özellikleri verdiklerini, tüm kimyasal maddelerin yangının büyümesini hızlandıran ısıyı azalttığını ve özellikle kireçli suyun yanma özelliklerini iyileştirmede oldukça etkili olduğunu tespit etmişlerdir. Zeinali ve ark. (2018) yaptıkları çalışmada, MDF levhalara Video Fire Analysis VFA (video yangın analiz) yöntemi ile teste tabi tutarak 1sı tahliye oranları ve duman çıkış oranlarını analiz etmişlerdir.

Odunsu malzemelerde yanma, tutuşma kabiliyeti, rengi, yoğunluğu, kokusu, tadı ve basınç direncine karşı dayanıklılığı ekstraktif madde miktarına bağlı olarak değişmektedir. Odunda ekstraktif madde miktarı azaldıkça yanma kabiliyeti de azalmaktadır. Lignin ve inorganik madde (kül) oranındaki artış yanma direncini azaltmaktadır (Peker ve Atılgan, 2015).

$\mathrm{Bu}$ çalışmada; EcoChem (FR) (Flame Retardand Chemistry) ticari adıyla bilinen yanma geciktirici özelliğe sahip, amonyum polifosfat ağırlıklı içeriği olan yangın geciktiricinin odun esaslı levha sektöründe seri üretim sürecine uygulanabilirliği gözlemlenmiş olup, üretilen orta yoğunlukta liflevhaların (MDF) yanma özellikleri incelenmiştir. Hem kontrol örnekleri hem de yanmayı geciktirici kimyasal maddeler ile üretilmiş MDF'ler, laboratuar ortamında direk aleve maruz bırakılarak karşılaştııılmıştır. Ayrıca termogravimetrik analiz yöntemi kullanılarak veriler sayısal olarak da incelenmiştir.

\section{Materyal ve Metot}

\subsection{Deney Levhaların Üretimi}

Yanmaya dayanıklı liflevhaların üretimleri Kastamonu Entegre Gebze Tesisleri'nde yapılmıştır. MDF levhaların üretiminde hammadde olarak \%70 kayın \%30 çam odunu kullanılmıştır. Üretim yeri Belçika'da bulunan EcoChem firması tarafindan MDF paneller için yanma geciktirici olarak üretilen amonyum polifosfat içerikli (MDP 6555 SE03) kimyasal kullanılmıştır. EcoChem; şeffaf çözelti halinde EN 13501-1(2009)' e göre Euroclass sınıfında üretilmiş çok düşük duman çıkışlı alev geciktiricidir. Melamin ve üre formaldehit reçineleri ile birlikte kullanılabilmektedir.

MDF üretiminde yanma geciktirici kimyasala daha iyi uyum gösterdiğinden melamin üre formaldehit (MÜF) tutkalı kullanılmıştır. \% 10-15 oranlarında melamin içeriğiyle hazırlanan bu tutkal yine Kastamonu Entegre Gebze tesisi bünyesinde bulunan tutkal ünitesinde hazırlanmıştır. Deney levhaları üretiminde katı madde oranı $\% 50$ olan MÜF tutkalından tam kuru lif ağırlığına göre \% 20 oranında kullanılmıştır. Levha üretimine sertleştirici madde olarak AKÇA firmasından katı halde tedarik edilen amonyum klorür kimyasalı, yine fabrikanın tutkal mutfağı adı verilen bölümünde sıcak suda \% 20'lik bir çözelti oluşturacak şekilde hazırlanarak tam kuru lif ağırlığına göre \% 0,5 oranında ilave edilmiştir. Parafin olarak MERCAN KỉMYA fabrikasından tedarik edilen \% 50 katı oranındaki sıvı parafinden, tam kuru lif ağırlığına göre \% 1 oranında ilave edilmiştir. Yanmayı geciktirici kimyasal olarak kullanılan katı madde oranı \% 50 olan EcoChem kimyasalından üretime yine tam kuru lif ağırlığına oranla \% 10 oranında verilmiştir.

Yanmaya karşı dayanıklı olarak üretilen levhaları normal levhalardan ayırmak amacıyla yanma özelliklerini etkilemeyen BASF firmasından tedarik edilen Basonly Red 545 adlı kırmızı renk boyadan üretilen levhalardaki kırmızı renk belli olacak ölçüde üretim gözlemlenerek tutkallama işlemi sırasında verilmiştir. MDF levhalar 18 mm kalınlığında standartlara uygun olarak piyasada en fazla tercih edilen $2100 \times 2800 \mathrm{~mm}$ ebatlarında üretilmiştir. Bu ebattaki levhaların farklı yerlerinden her test için ayrı ayrı 10 adet numune alınmıştır. Levha üretimleri fabrika ortamında uzunluğu 37 metre olan Küsters pres markalı sürekli preste gerçekleştirilmiş̧ir.

\subsection{Yanma Testleri}

\subsubsection{Tesis Laboratuvarında Uygulanan Sabit Aleve Karşı Dayanım Testi}

Test levhaları sıcaklığ $20 \pm 2{ }^{\circ} \mathrm{C}$ ve bağıl nemi $\% 65 \pm 3$ olan şartlardaki iklimlendirme odasında klimatize edilmiştir. Daha sonra tesis laboratuvarında TS EN 13501-1 (2007) standardına benzer olarak yanma dayanım testi uygulanmıştır.

TSE' de yapılan yanmaya dayanım testinde levhalar köşe duvardan yukarı doğru sabitlenerek taban kısmından sabit bir alev kaynağına maruz bırakılır ve sonuçlar gözlemlenir. 


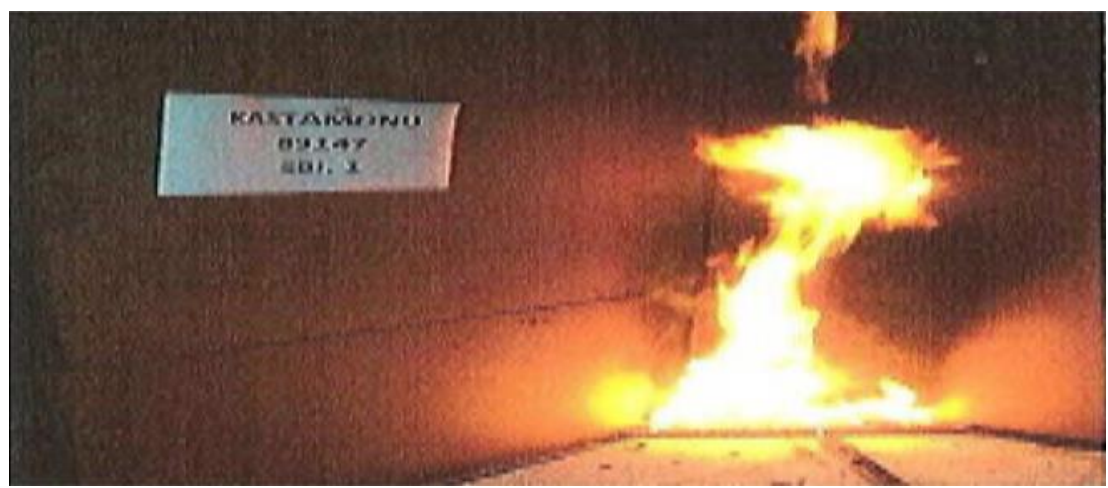

Şekil 2. TSE' de yapılan yanma dayanım testi.

TSE'de yapılan bu testten yola çıkılarak tesisin mekanik atölyesinde hazırlanan düzenekle hem kontrol örnekleri hem de yanmayı geciktirici kimyasal madde ile üretilmiş MDF'ler, laboratuar ortamında direk aleve maruz bırakılarak karşılaştırma yapılması sağlanmıştır.

Düzenek; alev kaynağı olan şalomayı ve levha numunesini sabit bir şekilde birbirlerine belli bir uzaklıkta tutacak bir profil ayaktan ibarettir. $9 \mathrm{~cm}$ geniş̧liğinde $50 \mathrm{~cm}$ uzunluğunda kesilen numune, aralarındaki uzaklık $10 \mathrm{~cm}$ mesafe olacak şekilde koyulan şaloma ile 2 dakika boyunca aleve maruz bırakılmış ve alev kaynağı kapatıldıktan sonraki sonuçlar gözlemlenmiştir.

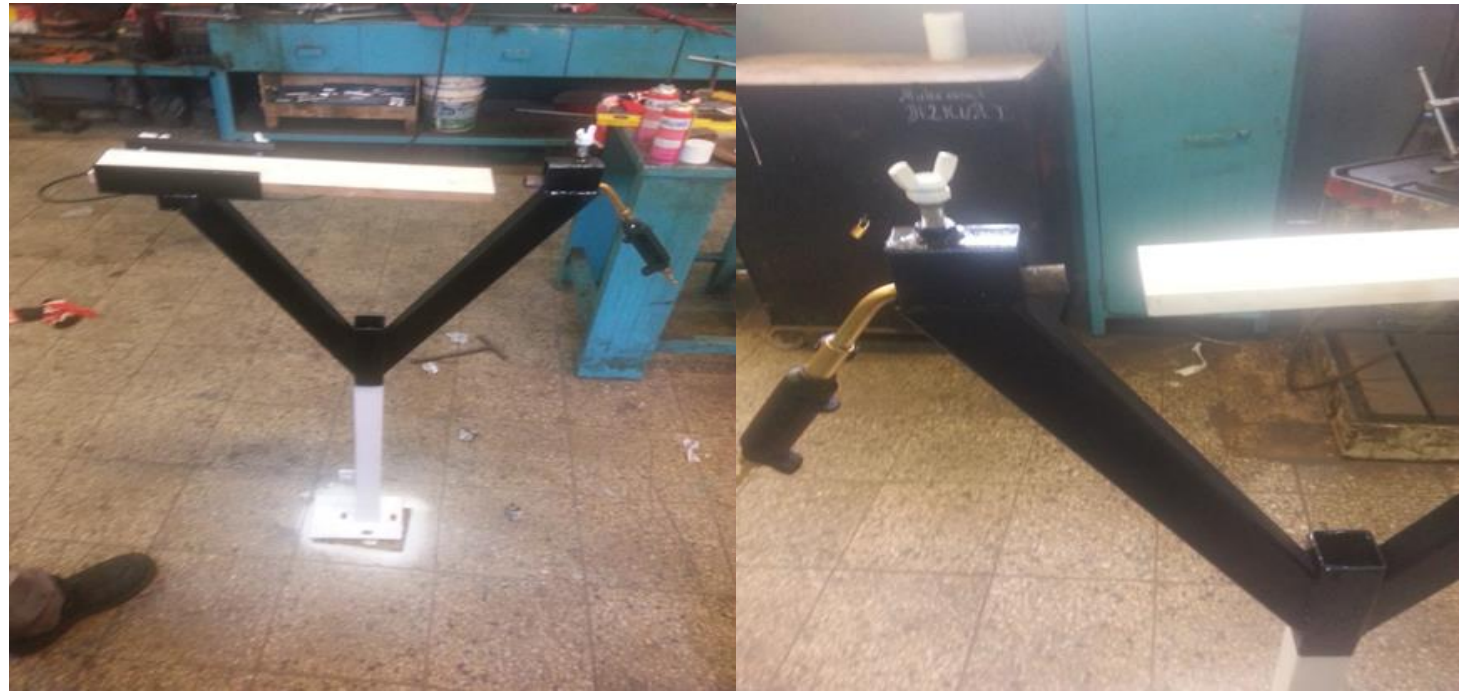

Şekil 3. Fabrikada hazırlanan yanma dayanım düzeneği.

\subsubsection{Termogravimetrik Analiz (TGA) ve Diferansiyel Termal Analiz (DTA)}

Üretilen levhaların enstrümental düzeyde yanma özelliklerini belirlemek amaciyla termogravimetrik analiz (TGA) yapılmıştır. TGA ölçümleri, Düzce Üniversitesi, Bilimsel ve Teknolojik Araştırmalar Uygulama ve Araştırma Merkezi laboratuvarlarında gerçekleştirilmiştir. TGA / DTA eşzamanlı bir tekniktir. Numunenin ağırlık değişimi ve referans ile arasındaki sıcaklık farkı kontrollü bir sıcaklık programı kullanılarak ölçülür. Bir malzemenin sıcaklık artışı ile bünyesinde meydana gelen termal ve gravimetrik değişimleri belirlemede kullanılır. Malzeme kütlesinde meydana gelen ağırlık değişimleri (su kaybı, organik madde uzaklaşması gibi) termogravimetri (TG), ekzotermik ya da endotermik reaksiyonlar sonucu meydana gelen sıcaklık değişimleri diferansiyel termal analiz (DTA) ile tespit edilir. DTA, erime, kaynama, parçalanma noktalarını yüksek doğrulukta tayin eder. Ayrıca kristallenme ve faz değişimleri hakkında bilgi verir. Normal şartlarda üretilen ve yanmayı geciktirici kimyasal madde ile üretilen levhalar küçük parçalara ayrılarak bir öğütücü yardımıyla ufak toz haline getirilmiştir. Daha sonra bu toz halindeki liflerden yaklaşık 0,2 mg gibi mikro düzeyde örnek alınarak TGA cihazı içerisine yerleştirilmiş ve enstrümental olarak ölçümleri gerçekleştirilmiştir. Örnek etrafında meydana gelen tutuşabilir ürünleri uzaklaştırmak üzere hava, azot veya diğer bir gaz dolaştırılmaktadır. Ağırlık kayıpları zamanın ve sıcaklığın fonksiyonu olarak kaydedilmektedir. 


\section{Bulgular ve Tartışma}

\subsection{Tesis Laboratuvarında Uygulanan Sabit Aleve Karşı Dayanım Testi}

Mekanik atölyede hazırlanan düzenek ile referans olması için test, öncelikle kontrol numunelerine uygulanmıştır. Kontrol numunelerinin sabit alev devam ederken ve kapatıldığında verdiği tepkiler gözlemlenerek, yanmayı geciktirici kimyasal madde ile üretilmiş numunelerle kıyaslanması için not edilmiştir.

Kontrol numunesinin aleve maruz kalması ile birlikte önce köşelerinde ve ardından yüzeyinde tutuşmanın başladığı görüldü. Sonrasında alevlenme levha yüzeyi boyunca hızlı bir şekilde ilerlemeye devam etmiştir. Alevlenmenin $50 \mathrm{~cm}$ boyunda hazırlanan levhanın diğer uç noktasına kadar ulaştığı görüldü. Bununla birlikte yapısı bozulan levhanın yerçekimi etkisi ile aşağıya doğru eğildiği gözlemlenmiştir. Aleve ilk maruz kaldığı anda kıvılcımlar attığı, kömürleşme devam ederken aleve direk temas eden yerden ateşli parçaların koparak düştüğü gözlemlenmiştir. Alev kaynağı kapatıldığında numunede yanma bir süre devam etti. Yanma bittiği anda yoğun bir dumanın çıktığı ve közlenme tamamen sönene kadar dumanın tütme şeklinde devam ettiği gözlemlendi. Numunenin; elle tutulacak kadar soğuduğunda mukavemetini, özellikle aleve direk maruz kalan kısımda tamamen yitirdiği ve ufalandığı tespit edildi. Yanmayı geciktirici kimyasal madde ile üretilmiş numunelere test uygulandığında alevde yayılma görülmedi. Alevin temas ettiği yüzey kadar kömürleşmenin olduğu fakat yüzey boyunca ilerlemediği, alevin temas ettiği alanla sınırlı kaldığı gözlemlendi. Kıvılcım ve alevli parça kopmaları görülmezken numune yapısını korudu. Alev kaynağı kapatıldığında levhada yok denebilecek kadar az seviyede bir duman oluşumu gözlemlendi. Kızaran levhada közlenme devam etmeyerek söndü. Numune elle tutulabilecek seviyeye kadar soğuduğunda mukavemetini koruduğu tespit edildi.

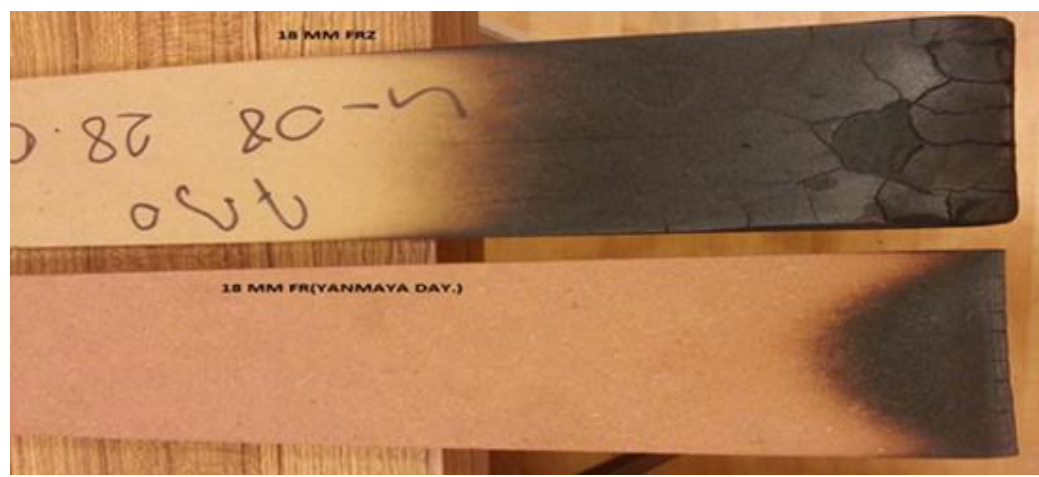

Şekil 4. $18 \mathrm{~mm}$ FR yanmaz levha ve $18 \mathrm{~mm}$ kontrol numunesinde yapılan yanmaya dayanım testi sonrasındaki görünüm.

Yanmayı geciktirici kimyasal madde ile üretilmiş numunelerde sadece görsel farklılık oluşturması için kullanılan kırmızı boyanın, yanmaya olumlu veya olumsuz bir etkisinin olup olmadığını görmek için aynı test yanmayı geciktirici kimyasal madde ile üretilmiş ve kırmızı boya eklenmiş numunelerde tekrarlandı. Yanma üzerine olumlu veya olumsuz bir etkisinin olmadığı tespit edildi.

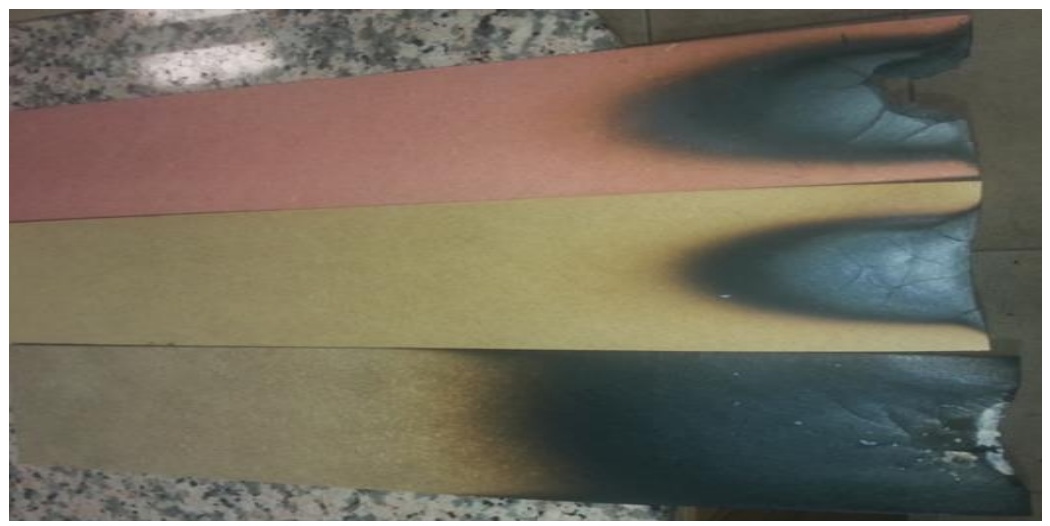

Şekil 5. $18 \mathrm{~mm}$ boyalı, boyasız ve kontrol numunelerinde yanma dayanım testi sonrasındaki görünüm.

Yapılan testler neticesinde üretilen kontrol numuneleri kendinden beklenen sonucu vermiştir. Ahşap esaslı malzemelerin yanmaya gösterdiği direncin düşük olduğu bilinmektedir. Üretilen MDF'lerde odunun lif haline getirilerek kullanılması, bu tutunmayı sağlayan bileşenlerin yanıcı içerikli olmaları alevlenmelerini 
hızlandırmaktadır. Bu malzemenin toplu yaşam alanında yaygın kullanılması yangın durumunda tehlikeyi üst seviyelere çıkarmaktadır. Bu tür kullanım alanlarında aleve maruz kaldıklarında yaşanabilecek olası problemler, test sonuçları baz alınarak düşünülürse, çıkan kıvılcımların ve alevli parça kopmalarının etrafa düşmesi ile yangın alanının hızla genişlemesine sebep olacağı söylenebilir. Alevin hızlı yayılması kontrol altına alınma süresini uzatacak ve müdahaleyi zorlaştıracaktır. Oluşan yoğun duman ve levha üretiminde kullanılan kimyasal bileşenlerin yanması ile oluşan gaz, kapalı yaşam alanında nefes alma refleksinin kısıtlanmasına yada tamamen ortadan kalkmasına sebep olabilir. Yanan ahşap malzemenin mukavemetini tamamen yitirmesi yer döşemesi olarak kullanıldığı alanlarda çökmelere neden olacaktır. Bu ve benzeri durumların oluşmaması için özellikle yaşam alanlarında tercih edilen ahşap esaslı malzemelerin yangın durumunda tam tersi tepkileri vermeleri istenir. Yanmayı geciktirici kimyasal madde ile üretilmiş numunelere yapılan test sonuçları bu ve benzeri durumların önüne geçilebileceğini göstermiştir. Ayrıca seri üretime uygulanabilirliği, istenilen kapasitede üretim olanağı sağlayabilir.

\subsection{Termogravimetrik Analiz (TGA) ve Diferansiyel Termal Analizi (DTA)}

Levhalarının yanmaya karşı direnç özelliklerini belirlemek için enstrümental analiz yöntemlerinden biri olan termogravimetrik analiz ve bu analiz ile eşzamanlı yapılan diferansiyel termal analiz, yanmayı geciktirici kimyasal madde ile üretilmiş numunelere ve kontrol numunelerine, önce ayr1 ayrı uygulanmış sonra karşılaştırmaları yapılmak suretiyle ilgili şekiller aşağıda verilmiştir. Grafiklerde görülen örnek gruplarında kontrol numunesi 'boyasız $18 \mathrm{~mm}$ ' olarak belirtilirken, yanmayı geciktirici kimyasal madde ile üretilmiş, sadece görsel farklılık oluşturması için kırmızı boya eklemesi yapılmış levha 'kırmızı' olarak ifade edilmiştir.

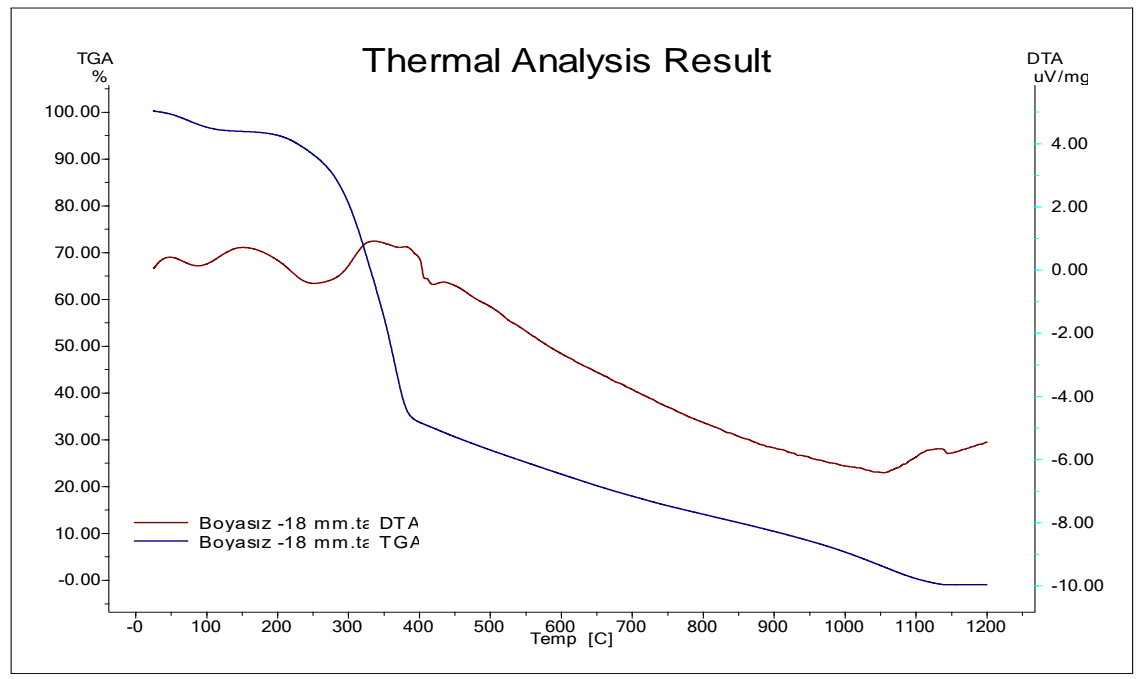

Şekil 6. Kontrol numunesinin TGA ve DTA grafiği

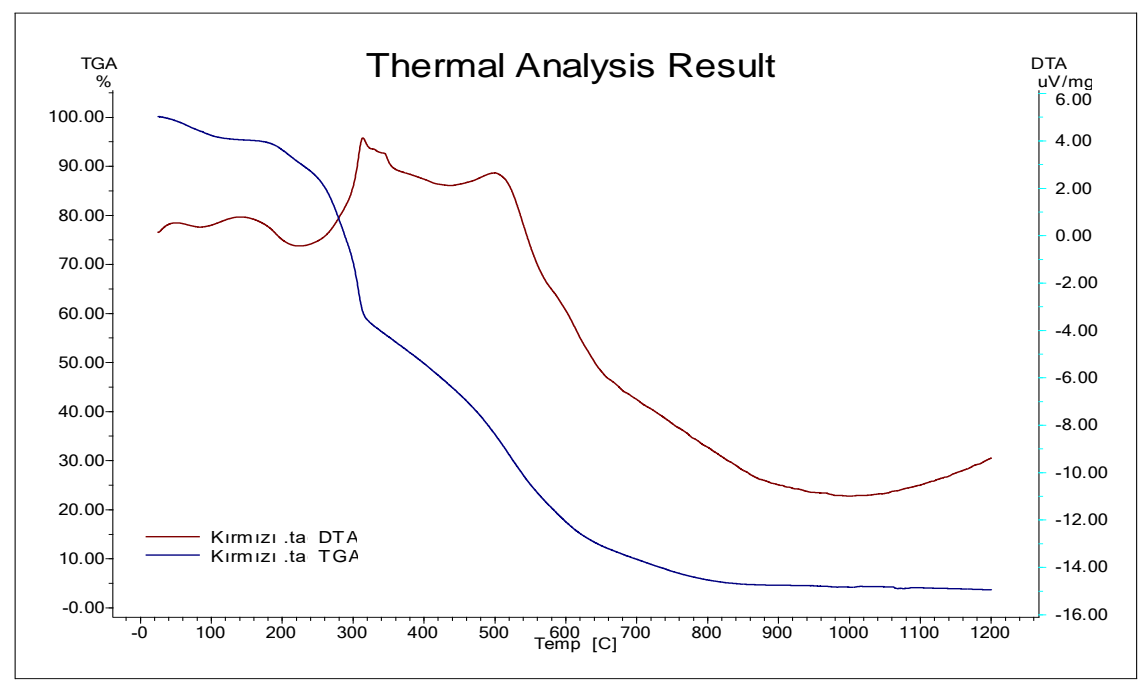

Şekil 7. Yanmayı geciktirici kimyasal madde ile üretilmiş levhanın TGA ve DTA grafiği 


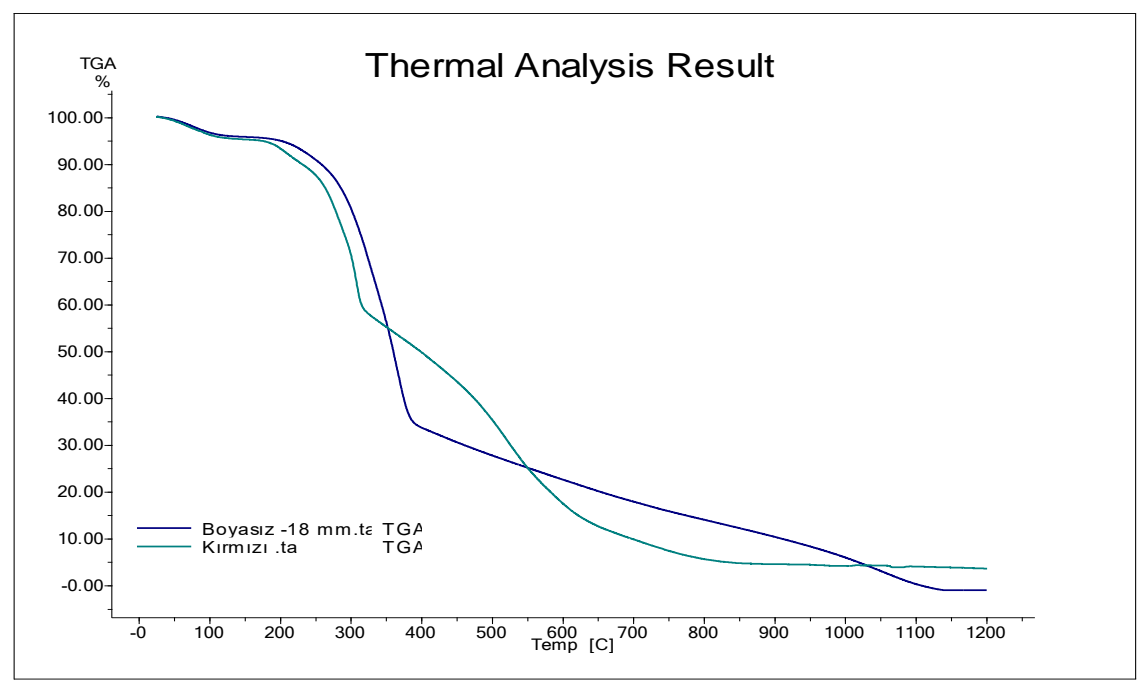

Şekil 8. Kontrol numunesinin ve yanmayı geciktirici kimyasal madde ile üretilmiş levhanın TGA grafiği.

Yukarıda verilen grafikler incelendiğinde analiz başlangıcında her iki örnek grubu içinde düşük sıcaklıklarda meydana gelen ağırlık kayıplarının numunelerdeki suyun uzaklaşmasından kaynaklı olduğu düşünülmektedir. Grafiklere göre en belirgin ani ağırlık kayıpları yanmayı geciktirici kimyasal madde ile üretilmiş levhalarda $200^{\circ} \mathrm{C}-300^{\circ} \mathrm{C}$ arasında iken, kontrol numunelerinde $200^{\circ} \mathrm{C}-400^{\circ} \mathrm{C}$ arasında gerçekleştiği görülmektedir. Bu durum odunda bulunan karbonhidratların bu sicaklıklarda bozunmasından kaynaklanmaktadır. (Tomak ve ark. 2011).

Yanmayı geciktirici kimyasal madde ile üretilmiş levhalarda elde edilen kalıntı kütle miktarının kontrol değerleriyle elde edilen kalıntı kütle miktarından daha yüksek bulunduğu, dolayısıyla da ağırlık kaybında azalma olduğu görülmektedir. Her iki örnek grubunun analiz sonucuna bakıldığında $1200^{\circ} \mathrm{C}$ 'de elde edilen tüm kalıntı madde miktarı değerlerinin kontrol grubunun değerinden daha yüksek olduğu bulunmuştur. Bu durum göz önüne alındığında; kullanılan yanmayı geciktirici kimyasal maddenin, yüksek sıcaklıklar altında örneğin ağırlık kaybını azalttığı ve dolayısıyla yanmaya karşı dayanımını arttırdığı ve iyi bir etkinlik sağladığı söylenebilir. Bu durum; tüm yangın geciktirici kimyasal maddenin odun ve odun esaslı maddelerin termal bozunma mekanizmasına müdahale ederek bozunma sıcaklıklarını etkilemesi ve düşük sıcaklıklarda dehidrasyon vb. reaksiyonları katalize ederek kömür tabakası oluşumunu artırmasının doğal bir sonucudur. (Grexa ve Lübke, 2001; Stevens, 2006; Liu ve ark. 2004; Wang ve ark. 2004).

\section{Sonuç ve Öneriler}

EcoChem (FR) bilinen yanma geciktirici özelliğe sahip amonyum polifosfat ile üretilen liflevhalar ile kontrol örnekleri direk aleve maruz bırakılarak karşılaştırılmıştır. FR kimyasalı içeren levhalarda alevin yayılmadığı görülmüş, parçada bozunma meydana gelmemiştir. Kontrol örnekleri ile karşılaştırıldığında kömürleşme oranı $\% 40$ daha azdır. TGA analiz yöntemi sonucunda kontrol örnekleri 400 0C'de \% 70 civarında yanma gösterirken, FR kimyasalı ile üretilen levhalarda bu oran \% 40 civarındadır. Buna göre amonyum polifosfat ile üretilen liflevhalar \% 30 oranında yanmaya karşı daha fazla direnç gösterdiği gözlenmiştir.

Levha üretiminde ülkemiz dünyada 5. sırada olup MDF üretiminde 3. en büyük üreticisi durumundadır (İstek ve ark. 2017). Bu durum ülkemizin levha üretimindeki önemini açıkça göstermektedir. Ülkemizde son yıllarda yanmaya dayanıklı özel levha talebinde bir artış olmuştur, dolayısıyla özel amaçlı levha üretimi konusunda çabalar artmıştır. Yanmaya karşı dirençli özel amaçlı levhaların üretilmesi, kullanımının teşvik edilmesi ve bu konuda daha fazla çalışma yapılması gerekmektedir.

\section{Kaynaklar}

1. Aydın DY, Gürü M, Ayar B, Çakanyıldırım Ç (2016). Bor Bileşiklerinin Alev Geciktirici ve Yüksek Sicaklığa Dayanıklı Pigment Olarak Uygulanabilirliği. Journal of Boron, 1(1): 33-39. 
2. Ayrılmış N, Dündar T, Candan Z, Akbulut T (2009). Wettabılıty of Fire Retardant Treated Laminated Veneer Lumber (LVL) Manufactured from Veneers Dried at Different Temperatures, Bioresources, 4 (4): $1536-1544$.

3. Baysal E (2003). Borlu Bileşikler ve Doğal Sepi Maddeleriyle Emprenye Edilen Sarıçam Odunun Yanma Özellikleri, Erciyes Üniversitesi, Fen Bilimleri Enstitüsü Dergisi, 19 (1-2): 59-69.

4. Demir A, Aydın İ (2016). Yangın Geciktirici Kimyasal Maddeler ile Emprenye İşleminin Odun ve Odun Esaslı Malzemelerin Teknolojik Özellikleri Üzerine Etkileri, Düzce Üniversitesi, Ormancılık Dergisi 12 (1): 96-104

5. Ellis DW, Rowell MR (1989). Flame-Retardant Treatment of Wood with a Diisocynate and an Oligomer Phosphonate, Wood and Fiber Science, 21 (4): 367-375.

6. EN 13501-1 (2009). Fire Classification of Construction Products and Building Elements - Part 1: Classification Using Data from Reaction to Fire Tests, European Standard.

7. Eroğlu H, Usta M (2000). Lif Levha Üretim Teknolojisi, K.T.Ü. Orman Fakültesi Yayın No: 200/30, ISBN: 975-6983-10-8, KTU Matbaas1, Trabzon.

8. Grexa O, Lübke H (2001). Flammability Parameters of Tested on Cone Calorimeter, Polymer Degradation and Stability, 74, 427-432.

9. Gu WJ., Zhang CG, Dong LS, Zhang YQ, Kong J (2007). Study on Preparation and Fire- Retardant Mechanism Analysis of Intumescent Flame-Retardant Coatings, Surface and Coatings Technology, (201): 7835-7841.

10. Hashim R, How LS, Kumar RN, Sulaiman O (2005). Some of The Properties of Flame Retardant Medium Density Fiberboard Made from Rubberwood and Recycled Containers Containing Aluminum Trihydroxide, Bioresource Technology (96): 1826-1831.

11. İstek A, Özlüsoylu İ, Çelik S, Gönül Ş (2017). Ahşap Esaslı Levha Sektöründe Kullanılan Yanma Geciktiriciler, UMDK Bildiriler Kitabı, (2): 160-169.

12. İstek A, Özlüsoylu İ, Kızılkaya A, (2017). Türkiye Ahşap Levha Sektör Analizi, Bartın Orman Fakültesi Dergisi, Bartın Üniversitesi, 19 (1): 132-138.

13. Kozlowski R, Mieleniak B, Helwig M, Przepiera A (1999). Flame Resistant Lignocellulosic-Mineral Composite Particleboards, Polymer Degredation and Stability, (64): 523-528.

14. Liu Q, Lv C, Yang Y, He F, Ling L (2004). Investigation on The Effects of Fire Retardants on The Thermal Decomposition of Wood-Derived Rayon Fiber in an Inert Atmosphere by ThermogravimetryMass Spectrometry, Thermochimica Acta, (419): 205-209.

15. Peker H, Atılgan A (2015). Doğal Bir Enerji Kaynağı Odun: Yanma Özelliği ve Koruma Yöntemleri, Afyon Kocatepe University Journal of Science and Engineering, (15): 1-12.

16. Rejeesh CR, Saju K K (2018). Relative Improvements in Flame Resistance of Coir Fiberboards Treated with Fire-Retardant Solution, Journal of Wood Science (64): 697-705

17. Spirckel M, Regnier N, Mortaigne B, Youssef B, Bunel C (2002). Thermal Degredation and Fire Performance of New Phosphonate Polyurethanes, Polymer Degredation and Stability, 78, 211-218.

18. Stevens R, Daan S, Bezemer R, Kranenbarg A (2006). The Structure-Activity Relationship of Fire Retardant Phosphorus Compounds in Wood, Polymer Degredation and Stability, (91): 832-841.

19. Tomak E, Hughes M, Yıldız UC, Viitanen H (2011). The Combined Effects of Boron and Oil Heat Treatment on Beech and Scots Pine Wood Properties, Part 1: Boron Leaching, Thermogravimetric Analysis and Chemical Composition, Journal of Materials Science, 46 (3): 598-607.

20. Ustaomer D, Usta M, Hiziroglu S (2008). Effect of Boron Treatment on Surface Characteristics of Medium Density Fiberboard (MDF), Journal of Materials Processing Technology 199: 440-444.

21. Wang Q, Li J, Winandy EJ (2004). Chemical Mechanism of Fire Retardance of Boric Acid on Wood, Wood Science Technology, (38): 375-389.

22. Zeinali D, Verstockt S, Beji T, Maragkos G, Degrootea J, Merci B (2018). Experimental Study of Corner Fires-Part II: Flame Spread over MDF Panels, Combustion and Flame (189): 491-505. 